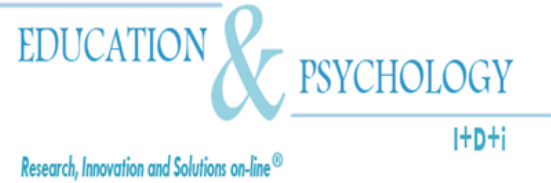

\title{
Use of syllabic logograms to help dyslexic readers of English visualize abstract words as pictures
}

\section{Alberto Sáez-Rodríguez}

Head of Projects, Dyslexia Institute,

Geneva

\section{Switzerland}




\begin{abstract}
Background. Dyslexics read concrete words better than abstract ones. As a result, one of the major problems facing dyslexics is the fact that only part of the information that they require to communicate is concrete, i.e. can easily be pictured.

Method. The experiment involved dyslexic third-grade, English-speaking children (8-yearolds) divided into two groups. One group was given syllabic logograms that supported drawings made by assembling stenographic strokes (syllables). The dyslexic control group did not receive the drawings. In this study we compared reaction times of two groups of dyslexic children of 22 pupils each, one supported with logograms and one without as a control group.
\end{abstract}

Results. The data gathered from these reading tests suggest that logograms can help dyslexic children form links between the syllables of a word and its corresponding image.

Conclusions. The results of the present study may aid in interpreting the data on the recognition of abstract words and production tasks with dyslexic children.

Keywords: Dyslexia; Reading disability; Unpicturable words; Logograms; Syllables and segmenting.

Abbreviations: $\mathrm{A}=$ age; $\mathrm{D}=$ dyslexic group; $\mathrm{FL}=$ familiarity coefficient; $\mathrm{M}=$ mean; $\mathrm{MSE}=$ mean square error; $\mathrm{RL}=$ latency time; $\mathrm{RTS}=$ Reaction Times; $\mathrm{SD}=$ standard deviation.

Received: 06/27/08 Initial Acceptance: 07/02/08 Final Acceptance: 02/24/09 


\section{Resumen}

Introducción. Los disléxicos leen mejor las palabras concretas que las abstractas. Por consiguiente, uno de los mayores problemas a los que se ven confrontados es el hecho de que tan sólo una parte de la información que necesitamos para comunicarnos es concreta, es decir, que puede ser dibujada.

Método. El presente experimento comprende alumnos disléxicos de habla inglesa de tercer grado (de 8 años de edad), repartidos en dos grupos. Uno de los grupos recibió la ayuda de logogramas silábicos que formaban dibujos armados con trazos estenográficos. El segundo grupo de niños disléxicos (grupo de control) no contó con la ayuda de dichos dibujos. Se compararon los tiempos de latencia en una tarea de denominación con dos grupos de niños disléxicos de 22 alumnos cada uno. Uno de los grupos tuvo el apoyo visual de logogramas, mientras que el otro no lo tuvo.

Resultados. Los datos obtenidos de las pruebas de lectura efectuadas sugieren que los logogramas pueden ayudar a los niños disléxicos a encontrar un nexo entre las sílabas de una palabra y la imagen correspondiente a la misma.

Conclusión. Los resultados de este trabajo pueden ayudar a entender los datos relativos al reconocimiento de las palabras abstractas, así como otras tareas llevadas a cabo con disléxicos.

Palabras Clave: Dislexia, incapacidad lectora, palabras indibujables, logogramas, sílabas y silabeo.

Recibido: 27/06/08 Aceptación inicial: 02/07/08 Aceptación final: 24/02/08 


\section{Introduction}

Recently, several lines of independent research and practice have come together to suggest a new way of treating dyslexia in preschool children, before the child has experienced difficulty in reading or spelling (Ellis \& Hooper, 2001; Noble \& McCandliss, 2005; Savage, Stuart \& Hill, 2002). In this novel approach to dyslexia, the condition is viewed not as a special learning disability, but as an alternative learning style. To further this effort, we present here a model of an alternative learning style for dealing with reading difficulties.

The cognitive deficit arising from dyslexia persists throughout life, although its severity and consequences on lifestyle vary considerably. Both retrospective studies (Scarborough, 1984) and prospective studies (Shaywitz, Holford \& Holahan, 1995) indicate that dyslexia is a chronic disorder, not a transitory maturational delay. For this reason, children who begin as poor readers tend to remain so throughout their lifetime. Nonetheless, the severity and lifestyle consequences of this reading deficit differ substantially in dyslexic children and dyslexic adults. In the case of an opaque orthograph, dyslexic adults generally have some reading ability, although they lack the fluency and accuracy of non-dyslexic subjects. Because of this lack of facility, the dyslexic must work harder during activities that involve reading and writing (Signorini, 1997).

Syllable additions, repetitions, substitutions, transpositions, omissions, and reversals errors were computed, using the same scoring used to assess word reading errors. Many authors consider the naming task to be the best for detecting reading problems (Olson et al, 1989; Perfetti, 1986; Siegel, 1992; Siegel \& Heaven, 1986; Tzivinikou, 2004). Nevertheless, evidence suggests that naming tasks are lexically mediated both in opaque orthographies $(\mathrm{Ba}-$ lota \& Chumbley, 1984; Baluch \& Besner, 1991; Forster \& Chambers, 1973; Saez, 2005; Seidenberg, Waters, Barnes, \& Tanenhaus, 1984; Viaggio, 2005) and in transparent ones (For review, see Sebastián, 1991). Being the naming task the best for detecting reading problems, the authors chosen the word-naming task in the present study.

As an evidence, Wimmer \& Hummer (1990) found that the majority of errors made by children learning to read German were nonsense words, in marked contrast to children learning to read English, whose errors were largely (the wrong) real words. The preponderance of 
nonsense word errors in German implies that the children were reading words indirectly by assembling pronunciations from grapheme-phoneme correspondences. Since reading requires identifying images and appropriately processing contrasts, this study examines the lack of an image as problem for dyslexics when syllables or particular words are not associated with images (Baluch \& Besner, 1991). For these reasons, all dyslexic children require therapeutic help to develop and optimize their abilities. Treatment should be intensive and long-term (Vygotsky, 1992). This treatment must be initiated early in development, if possible before the end of first grade in primary education (Herrera Nieto, 1999).

Of the 850 words in "The Basic English Word List", only 200 are picturable. Dyslexics read concrete words better than abstract words (Coltheart, 1978). Thus, only a small fraction of the information that a dyslexic person needs in order to communicate is easily picturable at all; this information includes objects, persons, places, and to some extent, actions, events and qualities. Originally formulated by Carroll and White (1973a, b), the original proposal of this theory has more recently been modified (Turner, Valentine \& Ellis, 1998). According to preliminary results from Noble and McCandliss (2005), the efficacy of intervention strategies can strongly affect students' levels of reading disability. Correlate to differences, the objectives of our work were to build on, and extend, the results of these investigators.

The Basic English Word List (850 Words) is divided into the following categories: general words (400), picturable words (200), descriptive words (100), opposites (50), and operations (100). These words all denote simple concepts commonly used in everyday life (Simple English Wikipedia).

\section{Hypotheses}

Our objective was to compare reader RTS to recognizing high-frequency words in a word-naming task using logograms supporting the images. Thus, our work differs from most of the existing literature, which considers only the effect of conventional pictures used as image support. Specifically, we examine two research questions:

(Q1)- How can subjects form mental pictures of small words (e.g., prepositions, articles, detached syllables)? 
(Q2)- Instead of picturing such words directly, do subjects create some kind of other link between syllables in a word and its corresponding image?

While the first question has been examined previously by other investigators (Ehri, 1995; Gupta \& Jamal, 2004; Rapp, Folk \& Tainturier, 2001), the second question attempts to give a new direction to dyslexia research.

\section{Method}

\section{Participants}

The group $(n=44)$ was recruited from normal children and reading-disabled children (third grade, 8 years old) nominated by psycho-pedagogues as educational counsellors. The group of dyslexics was divided into two of 22 pupils each, one supported with logograms and one without as a control group. Reading disability was assessed using various subtests, and the performance scores were used. The age and grade level for the normal children was third grade, and 8 years old.

All children had learned to read through a phonics-based curriculum, and they had been taught grapheme-phoneme correspondences in the first grade. This method gradually guides children from simple to complex correspondences and is the most common approach to reading instruction in English-speaking schools.

Excluded from the study were those children who had sensory problems, acquired neurological problems, or other problems traditionally used as exclusionary criteria for studies on learning disabilities. Since their young age, the children were enrolled with parental consent.

The children were asked to recognize high-frequency words in a word-naming task, and their RTs were measured. One group of children received both drawings and supporting syllabic logograms. The control group received only drawings, but no supporting syllabic logograms. 
Some may argue that syllabic logograms are composed of visual elements arranged in a variety of ways, and that they use the segmental phoneme (stenographic) principle of construction found in alphabetic languages. As a result, it should be easier to remember or guess the sound of alphabetic written words than to the meaning of ideographs, although it is relatively easier to remember or guess the meaning of ideographs than to the sound of alphabetic written words.

Another feature of syllabic logograms is that a single logogram may be used by multiple languages to represent words with similar meanings. Specific tasks are related directly to the hypothesis to be tested. In this study, the logogram-based tasks were designed to test specific hypotheses.

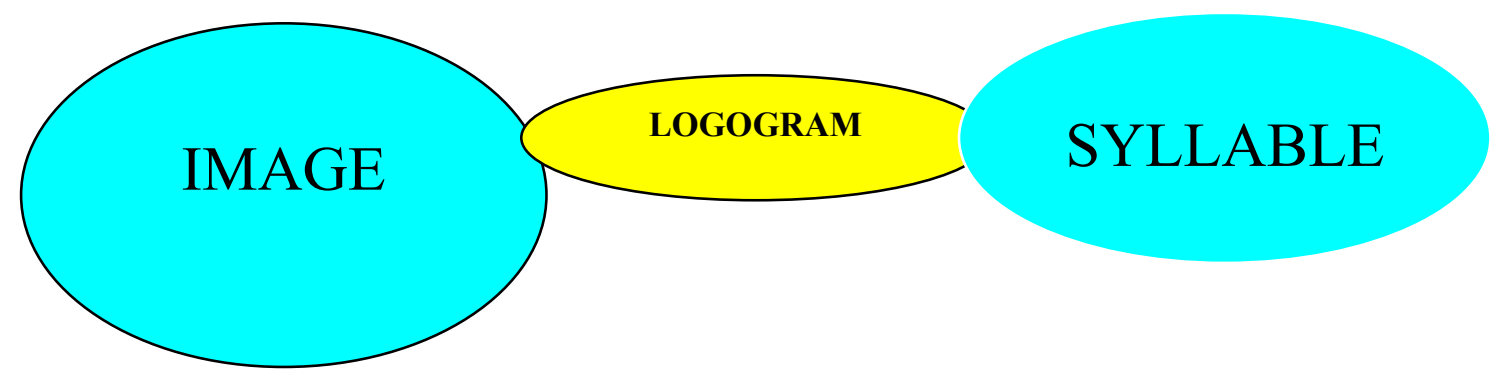

Figure 1. Link between syllables in a word and its corresponding matching image

Instruments, technical aspects of the experimental procedure

Figures (logograms) are created by assembling Pitman characters, which have simple geometric forms (Fig. 5-9, and Fig. 11-12). In the Pitman method all words are written according to their sounds and the consonant alphabet is based on the pattern of a crossed circle and uses paired thick and thin strokes. Thus, the type of stenographical alphabet used in this methodology (Fig. 3) is syllabic phonetic, i.e. it represents the basic articulations and sounds of the language. All of the elements comprising this alphabet come from geometry. Thus, straight and curved lines inspire strokes that represent syllables (see the Stenographical Alphabet below). Pitman characters have simple geometric forms, with curves that are taken from true circles. Pitman classified all the sounds in English and used this to develop his writing method. As shown in Figure 5, each vowel mark occupies one of three possible posi- 
tions on a consonant stroke: first (or initial), second (or middle), and third (or final). Thus, these are placed in any of three positions before or after a consonant sign according to their sound and where they occur in a word. In addition, word outlines can be written in three positions, above, on or below the line of writing, relating to the sound of the vowel.

This means that a dash in the middle position, the "uh" sound is written the same as the "oh" sound, and so forth. As shown in Figure 5, each vowel mark occupies one of three possible positions on a consonant stroke: first (above water), second (at water level), and third (under water) position.

Our specific experimental results (Figures 7-9) show several examples of unpicturable small words, in this case prepositions and articles. Subjects often made errors with these words, such as reading them twice, especially 'the', 'and', and 'of'. They also frequently added small words that were not in the text.

\begin{tabular}{|c|c|c|c|c|c|c|c|c|c|c|}
\hline $\begin{array}{c}\text { b } \\
\text { bed }\end{array}$ & $\begin{array}{c}\text { c } \\
\text { cat }\end{array}$ & $\begin{array}{c}\mathrm{d} \\
\mathrm{dog}\end{array}$ & $\begin{array}{c}f \\
\text { fish }\end{array}$ & $\underset{g}{g}$ & $\begin{array}{c}\text { h } \\
\text { hat }\end{array}$ & $\underset{\mathbf{j} u g}{\mathbf{j}}$ & $\begin{array}{c}\text { k } \\
\text { key }\end{array}$ & $\begin{array}{c}1 \\
\text { lion }\end{array}$ & man & $\begin{array}{c}\text { n } \\
\text { nest }\end{array}$ \\
\hline $\begin{array}{l}\text { p } \\
\text { pet }\end{array}$ & $\begin{array}{c}\mathbf{r} \\
\text { rock }\end{array}$ & $\begin{array}{c}\mathrm{s} \\
\text { sun }\end{array}$ & $\begin{array}{c}\mathbf{t} \\
\text { table }\end{array}$ & $\begin{array}{c}\mathrm{V} \\
\text { voice }\end{array}$ & $\begin{array}{l}\text { W } \\
\text { win }\end{array}$ & $\begin{array}{c}\text { y } \\
\text { yet }\end{array}$ & $\begin{array}{c}\text { z } \\
\text { zip }\end{array}$ & $\begin{array}{c}\text { a } \\
\text { apple }\end{array}$ & $\begin{array}{c}\mathrm{e} \\
\text { engine }\end{array}$ & $\begin{array}{c}\mathbf{i} \\
\text { insect }\end{array}$ \\
\hline $\begin{array}{c}0 \\
\text { hot }\end{array}$ & $\underset{\text { umbrella }}{\mathbf{u}}$ & $\begin{array}{c}æ \\
\text { angel }\end{array}$ & $\begin{array}{l}\epsilon \in \\
\text { eel }\end{array}$ & $\begin{array}{l}\text { ie } \\
\text { ice }\end{array}$ & $\begin{array}{c}\propto \\
\text { oat }\end{array}$ & $\begin{array}{c}\text { ue } \\
\text { uniform }\end{array}$ & $\begin{array}{c}\text { wh } \\
\text { wheel }\end{array}$ & $\begin{array}{c}\text { hh } \\
\text { chair }\end{array}$ & $\begin{array}{c}\text { fh } \\
\text { shoe }\end{array}$ & $\begin{array}{c}\text { th } \\
\text { thumb }\end{array}$ \\
\hline th & $\begin{array}{c}\text { au } \\
\text { auto }\end{array}$ & $\begin{array}{l}\text { oi } \\
\text { oil }\end{array}$ & $\begin{array}{l}\text { ou } \\
\text { owl }\end{array}$ & $\underset{\text { ring }}{\mathrm{rg}}$ & $\begin{array}{c}\mathbf{s} \\
\text { dogs }\end{array}$ & $\stackrel{3}{\text { garage }}$ & $\begin{array}{c}x \\
\text { bird }\end{array}$ & $\underset{\text { father }}{\mathbf{a}}$ & $\underset{\text { book }}{\omega}$ & $\begin{array}{l}\omega \\
\text { moon }\end{array}$ \\
\hline
\end{tabular}

Note: Phonemes. bead [i/i], bid [ I ], bed [є ], bad [æ], bod [p ], pawed [॰ ], bra [a /a ], $\operatorname{good}[u]$, booed $[\mathrm{u} / \mathrm{u}]$, bud $[\Lambda / \mathrm{e}]$, bird $\left[\mathrm{z}^{\circ} / 3\right]$, rosa's [ə], rose's [i $]$,

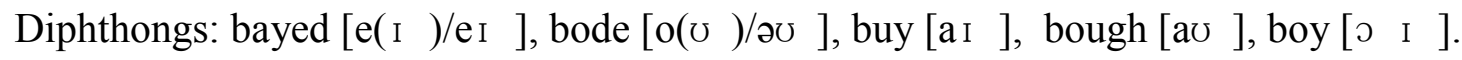

Figure 2. Logograms were made by assembling stenographic strokes for the following phonemes 


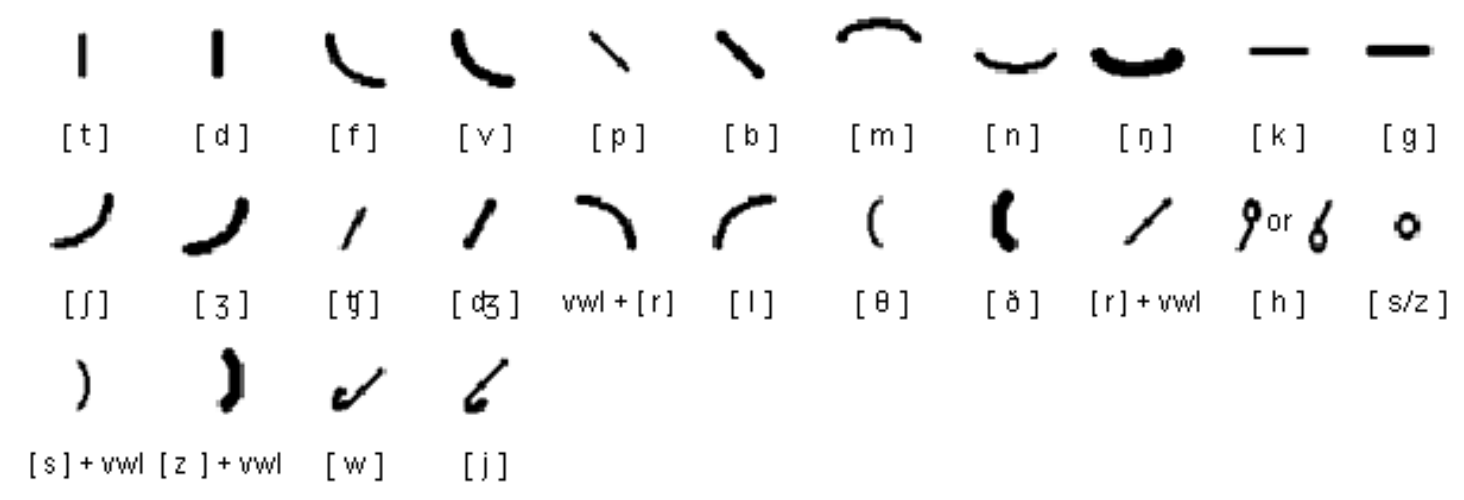

Figure 3. The Phonological Stenographic Alphabet [Isaac Pitman, 1837]

\begin{tabular}{|c|c|c|}
\hline \multicolumn{3}{|c|}{ SYLLABLE } \\
\hline \multirow{2}{*}{ BEGINNING } & NUCLEUS & CODA \\
\hline & vowel & \\
\hline
\end{tabular}

Figure 4. Syllable Structure in English

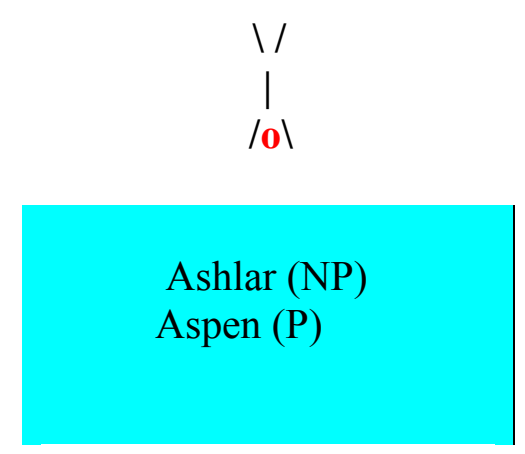

[æ]

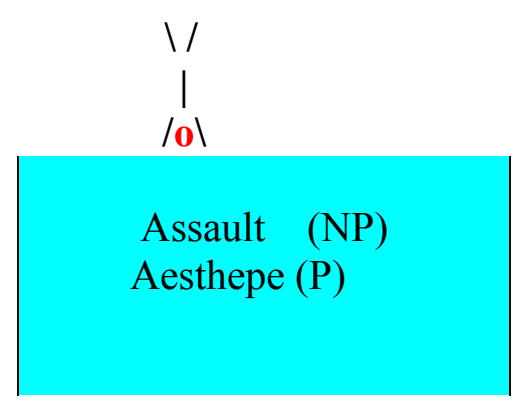

[i/i], [ə]

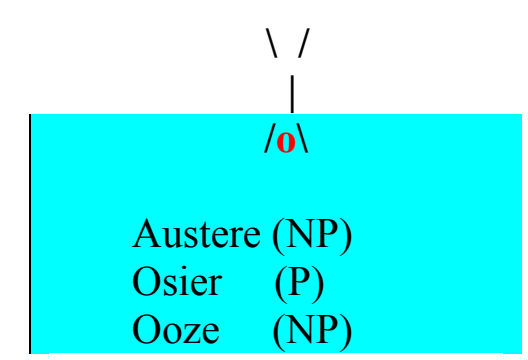

[० ], [0

\footnotetext{
P: $\quad$ picturable

NP: non picturable
}

Note: Phonemes. o:As per Pitman's stenographical alphabet, the circle (in the image is the bather's head) represents the sound: [vowel $+\mathrm{s} / \mathrm{z}]$

- First position: [æ/s/z] - Second position: $\quad$ [i/i/s/z], [ə/s/z] - Third position:[ว /s/z], [o ə/s/z]

Figure 5. Syllables of picturable words: the bather's head. Vowel sounds. Draw: a circle for the head 
Note: Likewise, letters or numbers mirror writing. Splitting the image into its composite syllables: $\mathrm{k} \backslash: \mathrm{p}): \mathrm{vw}): \mathrm{s} \mid: \mathrm{t}<: \mathrm{n}(:$ th $/: \mathrm{r}$

Figure 6. Picturable words (butterfly, the mirror effect)

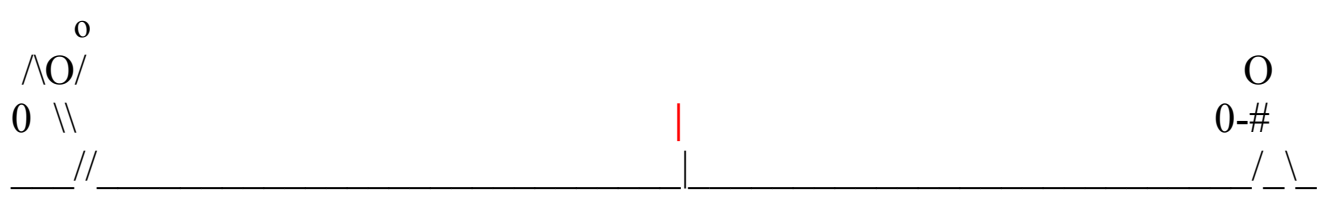

Figure 7. Game of tennis

Series of linking words

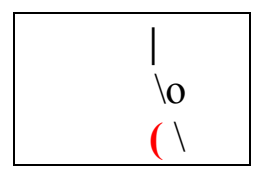

Figure 8. Preposition "this"

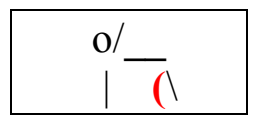

Figure 9. Preposition "that"

While the study was underway, the logogram system became available on DVD and $\mathrm{CD}$, which allowed further testing of the word-naming task. Logogram System was available on DVDs/CD's, for further performing the word naming task, and they were able to design on-line types of tasks in addition to the word-naming tasks they have already mentioned in the paper. 


\section{The word-naming task}

The task used in this study was designed to assess the speed and accuracy with which students in grades 3-8 identify words of average difficulty. The task involves showing a word on the screen and having the student to say the name of the word into a microphone (Fig.11).

Based on their performance on a set of words from "The Basic English Word List" (these words have been experimentally verified to be un-picturable), the students were first assessed for reading ability, then divided into groups, and then asked to do the word-naming task. The naming task consisted of reading aloud each verbal stimulus as it appeared one-byone on a computer screen. Each child has been asked to read the item as quickly as possible. We timed the RT to each stimulus, measuring from the moment the word appeared on the screen to when the subject pronounced the first reading sound.

The sound of the subject's voice triggered the recorder, which then stopped the computer's chronometer. The participants who were aided by supporting stenographic images were presented with the block of logograms, to encourage them to use specific strategy for finding a link between the image and syllables. When words are used in the same block, the most efficient strategy for performing the task is to use only the phonological route, as Álvarez, Carreiras and de Vega (1992) have suggested.

Different blocks of stimuli for the sample of reading-disabled children were subjected to reliability analysis between different tasks. In the cases of unpicturable words, reliability was 0.97 . For this experiment, the program was designed for use with a device that detects sounds within the range of human speech, but is not affected by the often significant level of background noise in these experiments (Escribano, 1991).

(1) The odd-word-out task. Based on the work of Bowey and Francis (1991), this task was designed to test awareness of intrasyllabic units using pictures. In our test, the examiner presented participants with a list of four logograms, instead of pictures, and asked the children to name them.

The instructions were: 
"I am going to show you some drawings. Look at these drawings. Tell me the names of the drawings. There is a sheep, a tennis player, a bear, and an eye. Now, we have to guess which drawing begins with a different sound. Here is a sheep, does it begin with $/ \mathrm{sh} /$ ? Yes, it does. Now, here is a bear, does it begin with /b/? Yes, it does. Now, here is an eye, does it begin with /e/? Yes, it does. Now, here is a spider, does it begin with /p/? No, it begins with an /s/."

The examiner did not provide any additional assistance, and the child was asked to identify the drawing beginning with a sound different from the one that was presented. After practicing with three examples, children had to complete this task for 10 items. Each item was associated with four pictures. The phonemes isolated for this task were the following: $/ \mathrm{r} /$, $/ \mathrm{l} /, / 11 /, / \mathrm{m} /, / \mathrm{t} /, / \mathrm{k} /$, and $/ \mathrm{p} /$.

(2) The phoneme segmentation test. In this test, children counted the phonemes of words that were presented orally while using counting aids, such as rods. In the examples, the examiner pronounced a word as he tapped each phoneme with the rod. The instructions were:

"Listen: 'toad'. How many parts does it have? It has two parts, doesn't it? The parts are /t//o/-/a/-/d/. Do you understand the game? If you need some help, you can use these rods."

The examiner did not provide any further assistance. Each word was presented individually and the examiner asked the children to identify the number of parts in each word. After completing two examples, children were asked to perform this task for 14 items. If their answer was wrong, he presents the mis-segmented version.

(3) The phoneme reversal test. In this test, the children counted the phonemes of words by reversing the order of segments in each word. In the examples, the examiner pronounced a word and gave the following instructions: "Listen, 'mass'. How many parts does it have? It has four parts, doesn't it? The parts are $/ \mathrm{m} /-/ \mathrm{a} /-/ \mathrm{s} /-/ \mathrm{s} /$. Do you understand the game?" The examiner did not provide any further help to the children. Each word was presented individually and the examiner asked the children to identify the number of parts in each word. This task also had two examples made up of 14 items. If their answer was wrong, he presents the mis-segmented version.

\section{Procedure}


We employed the regression-based procedure. The dependent variable was the RT for high-frequency words, controlling for the number of letters in each word. In other words, the RT for each stimulus (word) was divided by the number of letters in the word. The experiment consisted of a training phase and a test phase.

Provided that the syllabic logograms are unusual, and require considerable learning before they are conceivably of use, there was a pre-test training phase. The training phase consisted of a maximum of 72 trials, 12 for each possible reading errors of word (i.e., syllable additions, repetitions, transpositions, omissions, substitutions and reversals, randomly intermixed) and finished earliest if a criterion of 30 correct responses in 36 consecutive trials was achieved.

In this game you are going to see some words.

When a word appears on the screen, try and say the name of the word as QUICKLY and as ACCURATELY as you can into the microphone. Even if you are not sure of the word, try your best to say it.

If you have trouble with a word, try to say it silently to yourself before saying it out loud into the microphone.

The task items are arranged as 4 categories corresponding to $3,4,5$, and 6 letter words.

Do you have any questions? Let's try a few for practice.

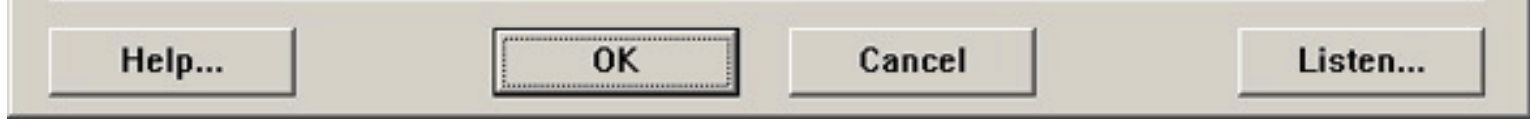

Figure 10. The word-naming task screen 


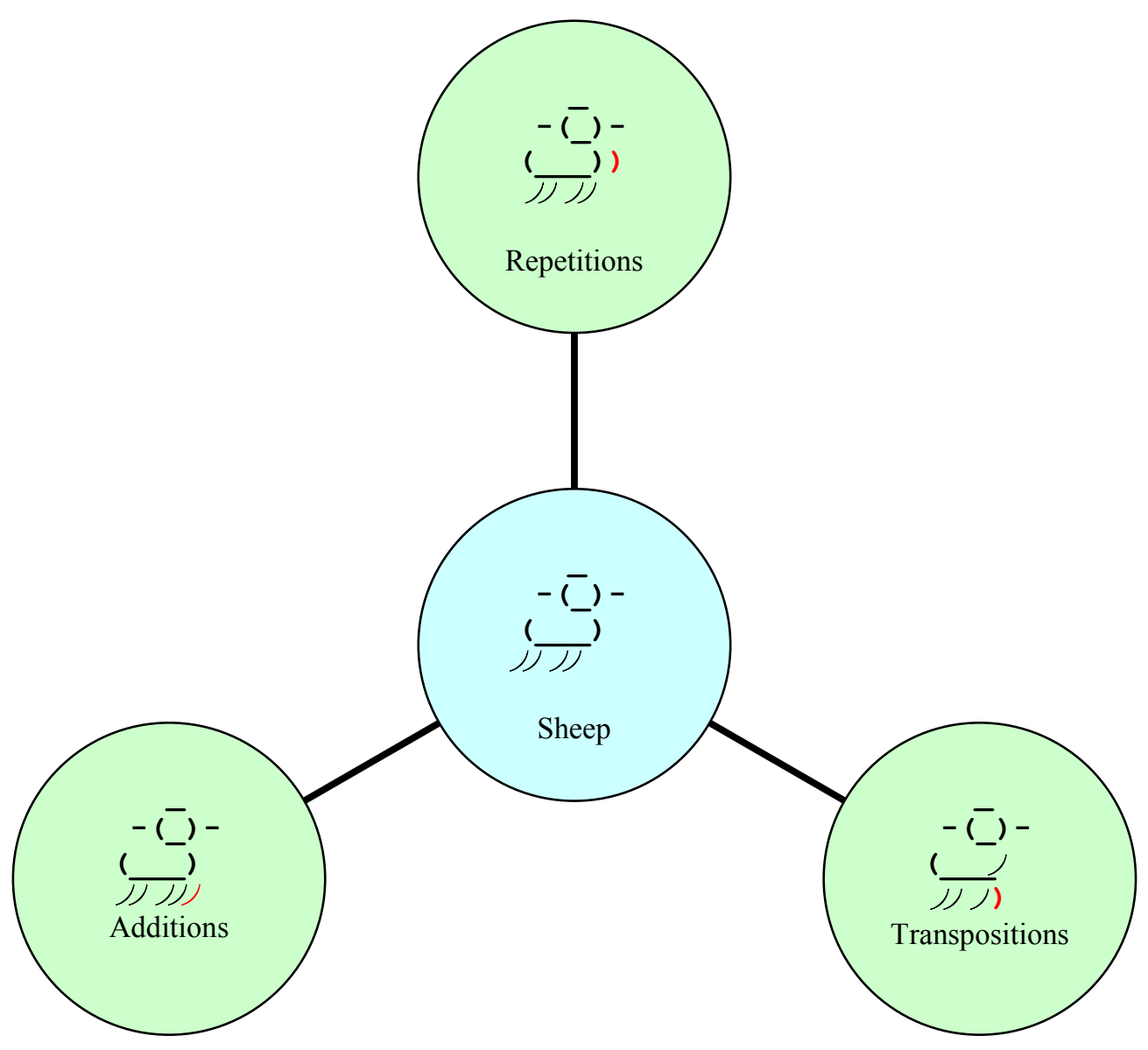

Figure 11. Syllable additions, repetitions, and transpositions

Note: The sheep has five legs, further decoding (according to Pitman's alphabet).

) : As stated above, this stroke (in the picture is the sheep's leg) represents the sound: [s/z] $\left[\int\right]$.

Additions: $\quad$ In the picture, the chest is drawn in the wrong position [ ) ].

Repetitions: In the picture, the chest is drawn twice [ ) ].

Transpositions: $\quad$ In the picture, a leg [ ) ] is drawn in stead of its chest, and its chest [)] is drawn instead of its leg. 


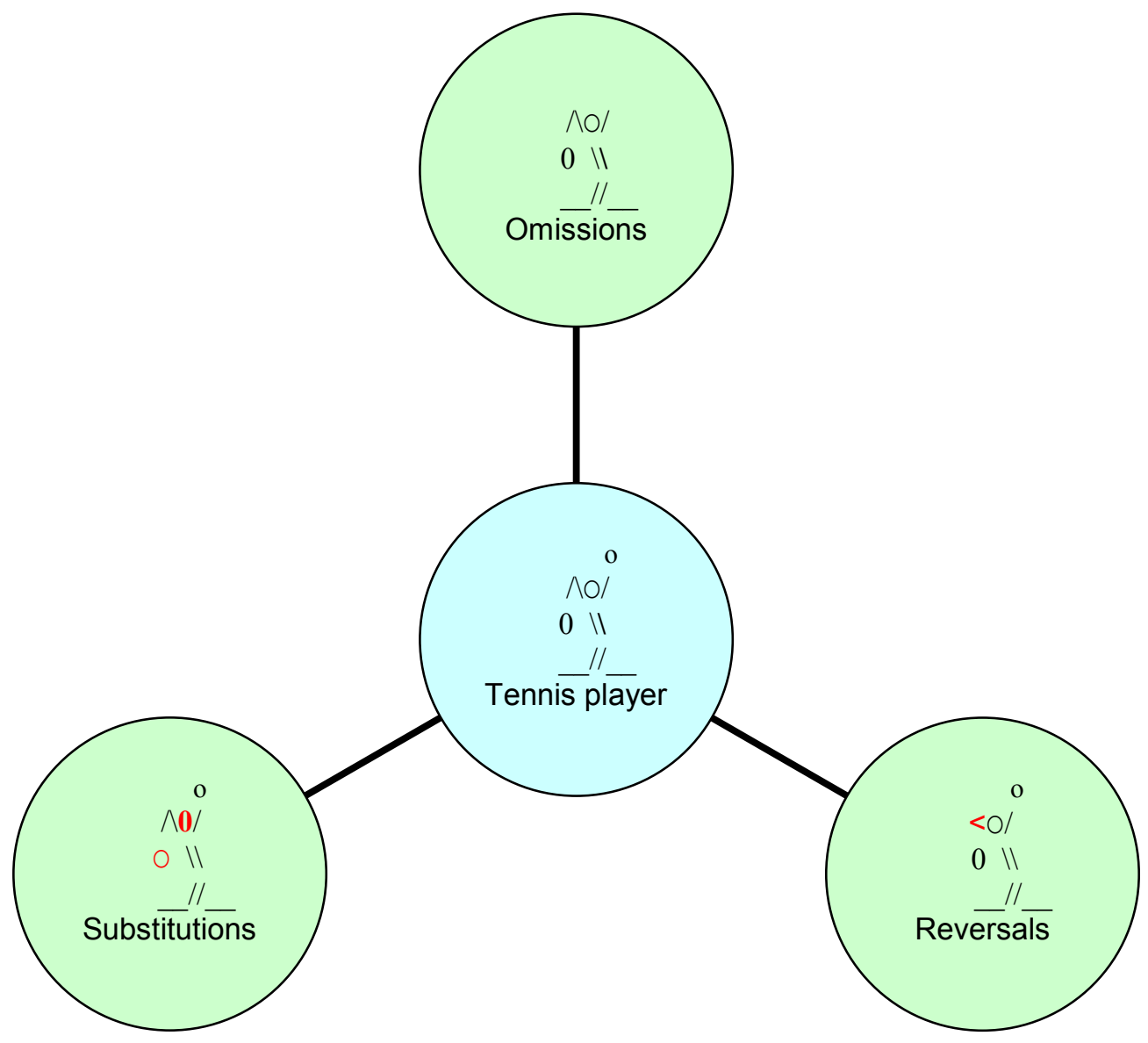

Figure 12. Syllable omissions, substitutions, and reversals

Note: Tennis player with racquet and ball, further decoding (according to Pitman's alphabet).

/: As stated above, this stroke (in the image is the player's leg) represents the sound: [p] /: As stated above, this stroke (in the image is the player's leg) represents the sound: [b]

0 : A circle for the head. As stated above, this stroke (in the image is the ball) represents the sound $[+\mathrm{s} / \mathrm{z}]$.

Omissions: In the picture, the ball [ 0 ] is missing.

Reversals: $\quad$ In the picture, the player's arm $[\wedge]$ is drawn in the wrong position $[<]$.

Substitutions: $\quad$ In the picture, the player's racquet [0] is drawn instead of his head: [ 0 ] 


\section{Data analysis}

Data reported in the figures and tables are expressed as means \pm SE. RTs to highfrequency word reading for both groups were evaluated by using a one-way analysis of variance to determine Body weight differences. A multivariate analysis of variance was performed on both groups. The dependent variables were: phonemic awareness, perception of speech, reading of words and syllables, verbal working memory, and speed in accessing phonological information.

\section{Results}

We carried out word-naming tasks with 22 dyslexic children, who were given visual aids, and with 22 control children, who did not have visual aids. Our results show that the two groups of students (dyslexic and control) had different reading levels (Figure 14). Tables 2-4 show the means and standard deviations of these variables for all the tests performed; the values are divided according to 'Group' and 'Time'. Fig. 14 shows reading-level-matched controls speed with picturable and un-picturable words and, for pre and post training test. The logogram group showed, in general, better reading skills from pre-test to post-test. With the effect of training on phonemic awareness, we found an interaction between groups and time $[F(2,47)=8.15 ; p<.001]$. These results indicate that phonemic awareness training that uses logograms for visual support can improve phonemic awareness of children, regardless of whether the children had been trained in speech perception. In analyzing the effect of training on the total score of reading words and syllables, we found an interaction between groups and time $[F(2,47)=7.91 ; p<.001]$. The dyslexic pupils who improved in their ability to read words and syllables were those who had been taught speech perception in combination with training in phonemic awareness using logograms. 


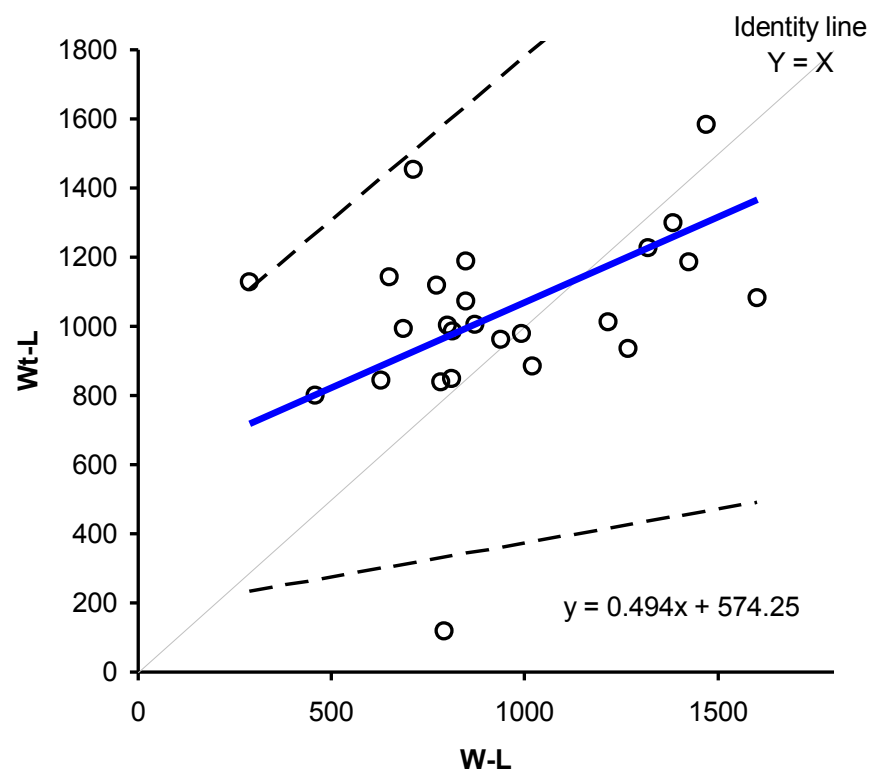

Figure 13. Stimuli for familiar picturable words used in the tests

Note: Based on 22 observations for both groups. W-L = with Logogram; Wt-L = without Logogram.

Table 1. Mean and Standard Deviations of both Groups in Each Reading Test

\begin{tabular}{lccc} 
& Categories & Wt-L & W-L \\
\hline Syllables & Un-picturable & 1.48 & 0.57 \\
\hline Little words & & & 0.51 \\
& & 3.64 & 0.56 \\
\hline Words & Un-picturable & 1.49 & 0.82 \\
& Picturable & 1.49 & 0.39 \\
\hline
\end{tabular}

Note (1): W-L = With Logogram; Wt-L = Without Logogram.

Note (2): Based on 22 observations for two groups of dyslexic readers of English with and without the syllabic logogram support respectively. 
Table 2. Reading-level-matched controls. Means and standard deviations for both with/without Logograms, in reading errors of word analyzed

\begin{tabular}{lcll}
\hline \multicolumn{1}{c}{ Reading errors } & Categories & W-L & Wt-L \\
\hline Additions & Picturable & .93 & .76 \\
& Un-picturable & 1.06 & 1.58 \\
& & & \\
\hline Substitutions & Picturable & $-9.53^{*}$ & $-7.06^{*}$ \\
& Un-picturable & $-5.44^{*}$ & $-7.55^{*}$ \\
& & & \\
\hline Transpositions & Picturable & $-6.86^{*}$ & $-5.16^{*}$ \\
& Un-picturable & $-5.14^{*}$ & $-4.13^{*}$ \\
& & & \\
\hline Reversals & Picturable & -2.10 & -1.23 \\
& Un-picturable & .88 & .77 \\
& & & \\
\hline Omissions & Picturable & $-5.66^{*}$ & $-4.22^{*}$ \\
& Un-picturable & $-6.03^{*}$ & $-5.34^{*}$ \\
& & & \\
& Picturable & 3.45 & 7.25 \\
\hline Repetitions & Un-picturable & 4.22 & 7.77 \\
\hline
\end{tabular}

Note (1): W-L = With Logogram Support; Wt-L = Without Logogram support.

Note (2): Based on 22 observations for two groups of dyslexic readers of English with/without the syllabic logogram support respectively. $* \mathrm{p}<.001$.

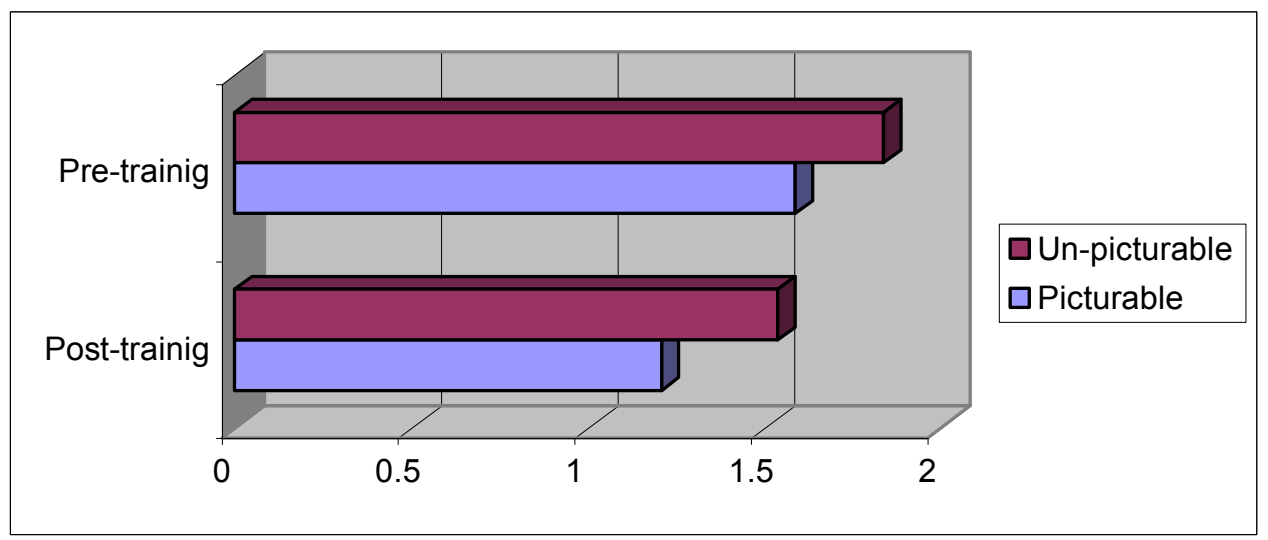

Figure 14. Mean results from the reading level-matched controls, before and after the training. Note: Group means of word RTs (in ms/letter) 
Table 3. Stimuli. List of familiar picturable words used in the tests

\begin{tabular}{llll}
\hline & FL & Wt-L & W-L \\
\hline Rice & 3.63 & 848 & 811 \\
Wedding & 3.76 & 1004 & 873 \\
Bed & 3.83 & 1128 & 289 \\
Eat & 3.76 & 843 & 628 \\
Cat & 3.90 & 1142 & 651 \\
Eye & 3.89 & 801 & 459 \\
Court & 3.67 & 1118 & 774 \\
Dish & 3.76 & 839 & 784 \\
Tree & 3.85 & 1300 & 1385 \\
Cinema & 3.78 & 1226 & 1319 \\
Fire & 3.85 & 884 & 1021 \\
Egg & 3.73 & 1454 & 712 \\
Play & 3.82 & 985 & 813 \\
Long & 3.69 & 1072 & 848 \\
Milk & 3.71 & 1012 & 1217 \\
Alphabet & 3.81 & 1584 & 1470 \\
Yellow & 3.65 & 1083 & 1601 \\
T-shirt & 3.81 & 119 & 793 \\
Room & 3.73 & 1185 & 1426 \\
Playdough & 3.78 & 961 & 939 \\
Elevator & 3.67 & 992 & 686 \\
Pencil & 3.75 & 1188 & 848 \\
Barefood & 3.76 & 1002 & 800 \\
Tear & 3.66 & 978 & 993 \\
Breakfast & 3.87 & 934 & 1268 \\
\hline & & &
\end{tabular}

Note: $\mathrm{FL}=$ familiarity coefficient;

W-L = Means with Logogram;

Wt-L $=$ Means without Logogram.

List of familiar un-picturable words, little words and consonants used in the tests.

\section{UN-PICTURABLE WORDS:}

Forward, Surname, Funny, Run, Christmas.

MISREADED LITTLE WORDS:

A, The, For, From, Then, There, Were, With, But.

\section{CONSONANT BLAST:}

tum, tem, tes, tet, tim, toc;

sab, sac, sal, sec, sen, sep, seg, sil, sim, sud, suf, sug

lan, las, lat, lav, lec, lem, lep, lev, lex, lib, lim, lin, lof

bal, bam, bod, bas, bom, bev, bis, bon, bos, bot, buf

peb, pel, pes, pol, pon, pom, pos, pud, pul, pum 


\section{Analysis of Errors}

In the analysis of words, the $F$ values for the different ANOVAs were as follows: additions, $F(2,106)=.55, p=.57$, MSE $=.98$; substitutions, $F(2,106)=37.9, p<.001$, MSE $=$ 559.7; transpositions, $F(2,106)=31.0, p<.001$, $\mathrm{MSE}=89.9$; reversals, $F(2,106)=1.13, p=$ $.32, \mathrm{MSE}=.16$; omissions, $F(2,106)=28.1, p<.001, \mathrm{MSE}=1030.3$; repetitions, $F(2,106)=$ $89.7, p<.001, \mathrm{MSE}=147.2$; and total number of errors, $F(2,106)=35.7, p<.001, \mathrm{MSE}=$ 2781.6. The dyslexic pupils who received syllabic logograms committed a significantly higher number of errors, particularly errors of omission and substitution, than did dyslexic pupils who did not have logograms. The groups showed no statistically significant differences in the number of addition or reversal errors that they committed.

\section{Conclusions and Discussion}

The results of this study show that the differences in reading performance shown by the two groups studied -dyslexic readers aided by a syllabic logogram and the comparison group that did not have logograms- correlated with their ability to link the syllables in a word to a corresponding image.

Bias may be introduced into studies that examine developmental changes by using tests of single word recognition in automatically generated contexts due to explicit and implicit processing of words and pseudowords by developmental dyslexics. Originally proposed by Carroll and White (1973a, 1973b), this idea has more recently inspired the hypothesis that the age at which a word is learned, or perhaps the order in which words are learned, is a powerful determinant of the speed with which lexical representations can be accessed and retrieved later in adulthood (Turner, Valentine \& Ellis, 1998).

The results of the present study may aid in interpreting the data on word recognition and production tasks (Turner, Valentine, \& Ellis, 1998) with dyslexic children. For instance, with regard to the task of naming pictures of objects, Oldfield and Wingfield (1965) reported a significant correlation between the speed of object naming and the frequency with which those names occur in the language, and these effects of word frequency on object naming have since been corroborated by many reports (Carroll \& White, 1973a, b; Ehri, 1995; Jescheniak \& Levelt, 1994). 
Results indicated that the participants who were aided by supporting stenographic images made significantly fewer errors when reading both pictural and un-pictural words (e.g., misreads little words, such as a for and, the for a, from for for, then for there, were for with), correlated with their ability to link the syllables in a word to a corresponding image. Our research hypotheses (Q1 and Q2) were thus corroborated. These findings have strong instructional and educational implications, e.g., in the strategies of teaching reading to dyslexic children.

Our results have taken dyslexia from what had previously been considered a hidden disability to one that is visible. It is in the line of most contemporary approaches to diagnosis and to teaching dyslexic children to read derive from a phonological model of how children gain access to print (Shaywitz, Morris, \& Shaywitz, 2008). In particular, knowledge of this model enables the reader to understand the basis and logic of current evidence-based reading instruction.

According to Turner et al. (1998), a person acquires much of his or her vocabulary in early childhood, although they continue to learn words throughout childhood and adulthood. Moreover, the acquisition of written word forms begins later than the acquisition of spoken word forms, and it may even spill over into late childhood. The results of the present work extends this research by arguing for an additional separation between, on the one hand, phonological representations involved in recognizing picturable words and producing spoken words, and on the other hand, orthographic representations (e.g., syllables, articles, etc.) that are involved in recognizing and producing written words.

More recently, Ho (2001) found that in the Chinese logographic writing system, a dyslexic reading pattern arises that differs from that of English-speaking readers, but is similar to that of Spanish readers. The proportion of children with a surface dyslexic pattern in Spanish and English-speaking was greater than the proportion of those with a phonological dyslexic pattern. The complexity in graphic appearance of Chinese characters would likely cause difficulties for children who are just learning to read. Whenever children use their lexical procedure to read, they must grapple with the complex structure of Chinese characters. In addition, although over $80 \%$ of Chinese characters are phonograms, the phonetic components of Chinese characters are unreliable. 


\section{Limitations}

While the present study has identified an important area in need of further research, the dyslexic group was recruited without taking into account different sub-types of dyslexia (e.g., surface dyslexia, phonological dyslexia, spelling dyslexia, and direct dyslexia). Nevertheless, the possible effect on the results is minimal, since the etiological basis suggests that reading disorders stem from difficulties in phonological processing, i.e. the brain's inability to translate images from the eyes completely and correctly to the ears and mouth (Barkley \& Mash, 1996).

Thus, while the present analyses demonstrated no obvious differences between both groups of dyslexic children, future studies should explore the extent to which volunteer samples, in general, are representative of the larger population of dyslexics. Another limitation is the fact that the dyslexic group was recruited without distinction of sex.

\section{References}

Álvarez, C., Carreiras, M., \& de Vega, M. (1992). Estudios estadísticos de la ortografía castellana: (1) la frecuencia silábica. Cognitiva, 4, 75-105.

Balota, D. A., \& Chumbley, J. I. (1984). Are lexical decisions a good measure of lexical access? The role of word frequency in the neglected decision stage. Journal of Experimental Psychology: Human Perception and Performance, 10, 340-357.

Baluch, B., \& Besner, D. (1991). Visual word recognition: Evidence for strategic control of lexical and nonlexical routines in oral reading. Journal of Experimental Psychology: Learning, Memory and Cognition, 17, 644-652.

Barkley, R. A. \& Mash, E. J. (1996). Child Psychopathology. New York: Guilford Press.

Bowey, J., \& Francis, J. (1991). Phonological analysis as a function of age and exposure to reading instruction. Applied Psycholinguistics, 12, 91-121.

Carroll, J. B., \& White, M. N. (1973a). Age of acquisition norms for 220 picturable nouns. Journal of Verbal Learning \& Verbal Behavior, 12, 563-576.

Carroll, J. B., \& White, M. N. (1973b). Word frequency and age-ofacquisition as determiners of picture-naming latency. Quarterly Journal of Experimental Psychology, 25, 85-95.

Coltheart, M. (1978). Lexical access in simple reading tasks: Strategies of information processing. In G. Underwood (Ed.), Strategies of information processing (pp.151-216). Academic Press (London). 
Ehri L. C. (1995). Phases of Development in Learning to Read by Sight. Journal of Research in Reading, 18, 116-125.

Ellis, N. C., Hooper A. M. (2001). Why Learning to Read is Easier in Welsh than in English: Orthographic Transparency Effects Evinced with Frequency-Matched Tests. Applied Psycholinguistics, 22, 571-599.

Escribano, J. L. (1991). Programa UNICEN [UNICEN Software]. Santa Cruz de Tenerife, Spain.

Forster, K. I., \& Chambers, S.M. (1973). Lexical access and naming time. Journal of Verbal Learning and Verbal Behavior, 12, 627-635.

Gupta A. \& Jamal G. (2004). Reading, Spelling Production and Bilingualism. Poster presented at International Conference on Cognitive Science. University of Al lahabad, Allahabad, India.

Herrera Nieto, M. (1999). El niño disléxico. Manual Moderno. Tercera Edición. México: Méndez.

Ho, F. J. (2001). Subtypes of dyslexia in Chinese orthography. Unpublished Doctoral Dissertation. The University of New South Wales, Sidney, Australia.

Jescheniak, J. D., \& Levelt, W. J. M. (1994). Word frequency effects in speech production: Retrieval of syntactic information and of phonological form. Journal of Experimental Psychology: Learning, Memory, \& Cognition, 20, 824-843.

Noble, K. G., McCandliss B. D. (2005). Reading development and impairment: behavioral, social, And neurobiological factors. Journal of Development Behavior Pediatric, 26(5), 370-378.

Oldfield, R. C., \& Wingfield, A. (1965). Response latencies in naming objects. Quarterly Journal of Experimental Psychology, 4, 272-281.

Olson, R. K., Wise, B., Conners, F., Rack, J., \& Fulker, D. (1989). Specific deficits in component reading and language skills: Genetic and environmental influences. Journal of LearningDisabilities, 22, 339-348.

Perfetti, C. A. (1986). Continuities in reading acquisition: Reading disability. Remedial and Special Education, 7, 11-21.

Rapp, B., Folk J. R. \& Tainturier, M. J. (2001). Word Reading. In Rapp B (ed.) The Handbook of Cognitive Neuropsychology: What Deficits Reveal about the Human Mind. Psychology. London: Taylor \& Francis.

Saez, A. (2005). Evaluation of image support in reading disability in the Spanish language. Electronic Journal of Research in Educational Psychology, 7, 3(3), 51-88.

Savage, R., Stuart M, Hill V., (2002). The Role of Scaffolding Errors in Reading Developmental:Evidence from a longitudinal and a Correlational Study. British Journal of Educational Psychology, 71, 1-13.

Scarborough, H. S. (1984). Continuity between childhood dyslexia and adult reading. British Journal of Psichology, 75, 329-48. 
Sebastián, N. (1991). Reading by analogy in a shallow orthography. Journal of Experimental Psychology: Human Perception and Performance, 17, 471-477.

Seidenberg, M. S., Waters, G. S., Barnes, M. A., \& Tanenhaus, M. K. (1984). When does Irregular spelling or pronunciation influence word recognition? Journal of Verbal Learning and Verbal Behavior, 23, 383-404.

Shaywitz, B. A, Holford T. R., \& Holahan J. M. (1995). A Matthew effect for IQ but not for reading: results from a longitudinal study, Reading Research Quarterly, 30, 894-906.

Shaywitz, S. E., Morris, R. \& Shaywitz, B. A. (2008). The Education of Dyslexic Children from Childhood to Young Adulthood. Annual Review of Psychology, 59, 451-75.

Siegel, L. S. (1992). An evaluation of the discrepancy definition of dyslexia. Journal of LearningDisabilities, 25, 618-629.

Siegel, L. S. \& Heaven, (1986). Phonological deficits in children with a reading disability. Canadian Journal of Special Education, 2, 45-54.

Signorini, A. (1997). Word reading in Spanish: A comparison between skilled and less Skilled beginning readers. Applied Psycholinguistics, 18, 319-344.

Turner, J. E., Valentine, T., \& Ellis, A.W. (1998). Contrasting effects of age of acquisition and word frequency on auditory and visual lexical decision. Memory \& Cognition, 26(6), 1282-1291.

Tzivinikou, S. (2004). Strengths and Weaknesses of Screening Reading Difficulties. Electronic Journal of Research in Educational Psychology, 4, 2(2), 59-74.

Viaggio, S. (2005). The Importance of the Metacommunicative Purposes of Communication, or Teaching Students to Listen and Speak Like Normal Human Beings. Meta, 50(1), $78-95$.

Vygotsky, L. S. (1992). Pensamiento y lenguaje. Buenos Aires: Ediciones Quinto.

Wimmer H, \& Hummer, P. (1990). How German Speaking First Graders Read and Spell: Doubts on the Logographic Stage. Applied Psycholinguistics, 11, 349-368. 